\title{
Cost-effectiveness of tiotropium versus
} glycopyrronium in moderate to very severe chronic obstructive pulmonary disease in Canada,
Spain, Sweden, and the UK

This article was published in the following Dove Press journal: ClinicoEconomics and Outcomes Research

II June 2016

Number of times this article has been viewed

\author{
Oskar Eklund' \\ Faraz Afzal ${ }^{2}$ \\ Fredrik Borgström' \\ Jason Flavin ${ }^{3}$ \\ Andrew Ternouth ${ }^{4}$ \\ Maria Eugenia Ojanguren ${ }^{5}$ \\ Carlos Crespo 5 \\ Mike Baldwin ${ }^{6}$ \\ 'Quantify Research AB, Stockholm, \\ Sweden; ${ }^{2}$ Boehringer Ingelheim, Asker, \\ Norway; ${ }^{3}$ Boehringer Ingelheim, \\ Burlington, ON, Canada; ${ }^{4}$ Boehringer \\ Ingelheim, Bracknell, Berkshire, UK; \\ ${ }^{5}$ Boehringer Ingelheim, Sant Cugat del \\ Vallès, Barcelona, Spain; ${ }^{6}$ Boehringer \\ Ingelheim, Ingelheim, Germany
}

Correspondence: Oskar Eklund Quantify Research AB, Hantverkargatan 8, II22। Stockholm, Sweden

Email: oskar.eklund@quantifyresearch.com
Objectives: Tiotropium (TIO), Spiriva ${ }^{\circledR}$ Handihaler ${ }^{\circledR}$, is a well-established bronchodilator, LAMA (long acting muscarinic antagonist), for the treatment of moderate to very severe chronic obstructive pulmonary disease (COPD). Clinical evidence from the SPARK trial suggests that TIO is superior to glycopyrronium (GLY), Seebri ${ }^{\circledR}$ Breezhaler ${ }^{\circledR}$, in terms of severe exacerbations. This modeling study assessed the cost-effectiveness of TIO versus GLY for Canada (CAN), Spain (ESP), Sweden (SWE), and the UK, making use of this new clinical evidence.

Methods: A Markov cohort model, with moderate to very severe (Global Initiative for Chronic Obstructive Lung Disease II-IV) COPD patients, was populated with efficacy data from the Understanding Potential Long-term Impacts on Function with Tiotropium (UPLIFT) and SPARK trials as well as costs, utilities, and epidemiological data relevant for each country. Treatment efficacy was modeled as improvements in lung function, quality-adjusted life years (QALYs), and as a lowering of the risk of exacerbations (rate of exacerbations). Risks of exacerbations differed between cohorts based on data from SPARK. Health and cost outcomes were simulated over an approximate lifetime horizon, starting from the age of 65 years. Robustness of results was validated in deterministic sensitivity analyses.

Results: Over the lifetime horizon, patients treated with TIO accumulated -623 (CAN), 1,066 (ESP), 1,137 (SWE), and-169 (UK), respectively, in incremental costs (€2014). TIO generated better health outcomes compared to GLY in all countries, 0.21 (CAN), 0.25 (ESP), 0.23 (SWE), and 0.23 (UK) in incremental QALYs. The cost per QALY gained was found to be $€ 4,281$ and $€ 1,137$ for ESP and SWE, respectively, while TIO was found to be cost saving in CAN and the UK. The results were mainly driven by the relative risk of severe exacerbations found in SPARK (GLY/TIO relative risk: 1.43, 95\% confidence interval: 1.05-1.97, $P=0.025$ ).

Conclusion: The results from this study show that TIO is a cost-effective treatment compared to GLY in moderate to very severe COPD. The cost per QALY is well below the existing implicit and explicit willingness-to-pay thresholds.

Keywords: COPD, exacerbations, tiotropium, glycopyrronium, cost-effectiveness, Markov cohort model

\section{Introduction}

\section{Background}

Chronic obstructive pulmonary disease (COPD) is a chronic respiratory disease affecting $\sim 5 \%-10 \%$ of the adult population. ${ }^{1-4}$ In the European Union, COPD stands 
for $56 \%$ of the direct costs associated with respiratory diseases. ${ }^{5}$ Respiratory diseases, in turn, represent $6 \%$ of the total health care budget. ${ }^{5}$ This means that the estimated total cost of COPD in the European Union is $€ 38.6$ billion. ${ }^{5}$ In the US, the calculated annual direct cost burden of COPD amounts to $\$ 30$ billion. $^{6}$ In addition to the high direct cost burden, indirect costs are large and amount to $\$ 20$ billion in lost production every year. ${ }^{6}$ Exacerbations, that is, "acute and sustained worsening of the patient's respiratory symptoms beyond normal day-to-day variations that result in an increased need for medication [...]", are important drivers of COPD-related costs. ${ }^{7}$ Exacerbations on the acute and severe end of the spectrum are the most common causes for COPD-related hospitalizations in the US and UK, and hospitalizations, in turn, represent $54 \%$ of direct COPD-related costs. $^{8-10}$ Besides costs, exacerbations increase mortality ${ }^{11,12}$ and decrease health-related quality of life ${ }^{13,14}$ in COPD patients. Thus, COPD exacerbations represent a significant economic and clinical burden.

Pharmacologic therapy in moderate to severe COPD includes long-acting bronchodilators, long-acting $\beta_{2}$ agonists (LABAs), or LAMAs (long acting muscarinic antagonist). Inhaled corticosteroids (ICSs) and antibiotics can be used alone or in combination with bronchodilators to treat and mitigate the effects of exacerbations. According to the Global Initiative for Chronic Obstructive Lung Disease (GOLD) recommendations, the first choice of therapy for patients with moderate to severe COPD is LAMA or LABA therapy alone. ${ }^{5}$ In high-risk patients, that is, those at risk of exacerbations, ICS can be added to the LABA monotherapy. Short-acting bronchodilators, either in the form of an anticholinergic or a $\beta_{2}$ agonist, are typically administered as needed to relieve symptoms in the short term.

Several studies have shown that regular use of LAMAs, LABAs, and ICSs can lower the incidence and effect of exacerbations. ${ }^{15}$ In a 4-year, randomized, double-blind trial (Understanding Potential Long-term Impacts on Function with Tiotropium [UPLIFT]), tiotropium (TIO) significantly improved lung function (forced expiratory volume in 1 second $\left[\mathrm{FEV}_{1}\right]$ ) and lowered the risk of exacerbations when added to usual non-LAMA care, compared to usual non-LAMA care alone. ${ }^{16}$ Evidence from recent studies also suggests that TIO is superior to both once-daily ${ }^{17}$ and twicedaily ${ }^{18}$ administered LABAs when it comes to preventing exacerbations. Furthermore, in a recent head-to-head trial (SPARK), patients treated with TIO had lower rates of severe exacerbations, that is, those leading to hospitalization, than patients treated with glycopyrronium (GLY). ${ }^{19}$
TIO has been shown to be a cost-effective treatment compared to usual care in the management of COPD in a number of countries. ${ }^{20}$ However, evidence on the cost-effectiveness of TIO versus other LAMAs has been scarce. With the publication of SPARK results in addition to previous trials, it is now possible to compare TIO and GLY head-to-head. ${ }^{19}$ The primary objective of this study was to analyze the costeffectiveness of TIO compared to GLY in Canada (CAN), Spain (ESP), Sweden (SWE), and the UK using data from the UPLIFT ${ }^{16}$ and SPARK ${ }^{19}$ trials.

\section{UPLIFT and SPARK trials}

UPLIFT $^{16}$ was a randomized, double-blind, placebo-controlled study, investigating the efficacy of TIO when added to non-LAMA usual care (placebo) compared to placebo alone. A total of 5,993 patients (mean age, 65 \pm 8 years), with an $\mathrm{FEV}_{1}$ of $70 \%$ or less, that is, moderate to very severe COPD (GOLD II-IV), after bronchodilation and a ratio of $\mathrm{FEV}_{1}$ to forced vital capacity of $70 \%$ or less, were studied over a 4-year period. Co-primary end points were the rate of decline in mean $\mathrm{FEV}_{1}$ before and after bronchodilation beginning on day 30. Secondary end points were, among other things, rates of exacerbations, measures of forced vital capacity, changes in St George's Respiratory Questionnaire responses, and mortality. The main findings were that mean absolute improvements in $\mathrm{FEV}_{1}$ in the TIO group were maintained throughout the trial as compared to placebo $(P<0.001)$. In addition, the number of exacerbations per patient-year declined in favor of TIO. ${ }^{16}$

SPARK ${ }^{19}$ was a randomized parallel group study investigating the relative efficacy of QVA149 (GLY and indacaterol combination) versus GLY monotherapy and TIO monotherapy. A total of 2,224 patients were enrolled, aged 40 years or more, with severe or very severe COPD (GOLD III-IV) and one or more moderate COPD exacerbations in the last year. Results showed that there was no significant difference between GLY and TIO in preventing mild (GLY/TIO relative risk [RR]: 0.99, $P=0.90)$ and moderate or severe (GLY/ TIO RR: 1.03, $P=0.68)$ exacerbations. However, in the case of severe exacerbations (SevEx) alone, TIO was superior to GLY (GLY/TIO RR SevEx: 1.43, $P=0.025$ ).

\section{Methods COPD models}

Chronic and slowly progressing diseases such as COPD are well characterized in a simple Markov cohort framework. Indeed, most cost-effectiveness models in the published COPD literature are Markov cohort models. ${ }^{7,21}$ In most cases, 
model health states are constructed around the established GOLD classification of severity of airflow limitation..$^{22}$ This classification is based on four groups: mild (GOLD I FEV $\geq 80 \%$ ), moderate (GOLD II $50 \% \leq \mathrm{FEV}_{1}<80 \%$ ), severe (GOLD III $30 \% \leq \mathrm{FEV}_{1}<50 \%$ ), and very severe (GOLD IV $\left.\mathrm{FEV}_{1}<30 \%\right) \mathrm{COPD}$, each representing an interval of postbronchodilator $\mathrm{FEV}_{1}$, a measure of airflow. ${ }^{5}$ Some models ${ }^{23,24}$ also incorporate costs and effects of exacerbations, typically modeled as events occurring within the health (GOLD) states. This makes it possible to add baseline costs and outcomes associated with each health state as well as additional eventspecific costs and outcomes associated with exacerbations. This study used data obtained from published sources of UPLIFT and SPARK trials. These trials had all the necessary regulatory and ethical approvals in place. As this is a modeling study without any primary data collected, we do not need regulatory/ethical approval.

\section{Model description}

The Markov cohort model, shown in Figure 1, was built in TreeAge Pro Suite 2014 and has been described before in an analysis for SWE. ${ }^{25}$ The model was based on three health states (GOLD II, GOLD III, and GOLD IV), between which the cohort of patients could move with varying probabilities. Patients were modeled from the age of treatment initiation (65 years old) until they deceased or reached the end of the simulation (100 years). Two cohorts were analyzed, one receiving standard treatment with TIO $18 \mu \mathrm{g}$ (Spiriva ${ }^{\circledR}$ HandiHaler $($ ) and one receiving standard treatment with GLY $44 \mu \mathrm{g}$ (Seebrii ${ }^{\circledR}$ Breezhaler $\left.{ }^{\circledR}\right)$. Upon entering the model, both

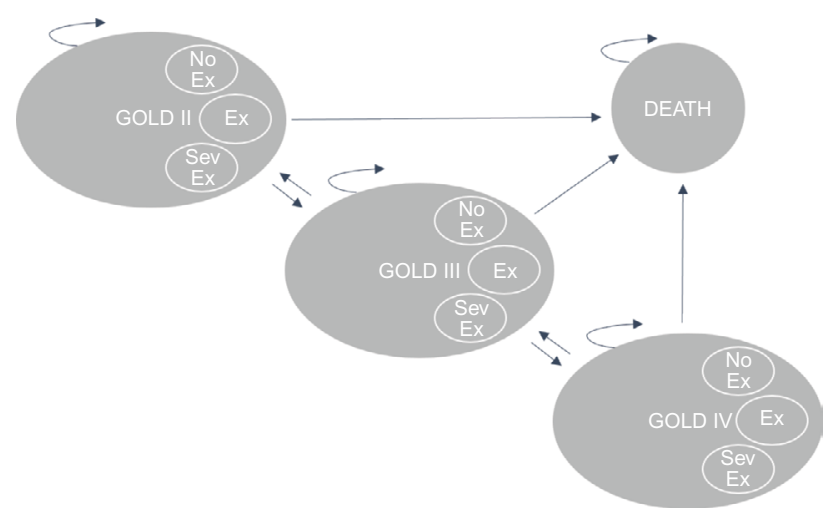

Figure I Markov model state transition diagram.

Note: The arrows reflect the fact that a patient can remain in the same state for several cycles.

Abbreviations: GOLD, Global Initiative for Chronic Obstructive Lung Disease; GOLD II, GOLD classification indicating moderate COPD; COPD, chronic obstructive pulmonary disease; GOLD III, GOLD classification indicating severe COPD; GOLD IV, GOLD classification indicating very severe COPD; No Ex, no exacerbation; Ex, exacerbation; SevEx, severe exacerbation. cohorts of patients were distributed across the separate states according to the observed distributions found in UPLIFT (GII: 48\%, GIII: 44\%, GIV: $8 \%) .{ }^{16}$ Within each 3-month cycle, the patients could then experience any one of the following three events: 1) no exacerbation, 2) nonsevere exacerbation, or 3) severe exacerbation. Each event occurred with certain statespecific probabilities. Based on trial data from UPLIFT ${ }^{16}$ and SPARK,${ }^{19}$ these probabilities were varied across the treatment alternatives in order to reflect relative efficacy of the treatment alternatives. Each state and event combination had different costs and effects associated with that particular combination. Subsequent to each event, the patients could either die or transition to one of the other two health states for a new 3-month cycle to begin.Within each state, a patient can experience any one of the following events: 1) no exacerbation (No), 2) nonsevere exacerbation (Ex), 3) severe exacerbation (Sev).

\section{Target patient population}

The base case model population was assumed to be similar to that of the UPLIFT ${ }^{16}$ trial in terms of age (65 years), disease state (GOLD II-IV), risks of exacerbations, and the usual (non-LAMA) care received besides the two treatment interventions modeled. In addition, to accurately reflect the real-world characteristics of COPD patients, the model was populated with mortality data representative for each country's patient population.

\section{Clinical data}

Transition probabilities and risks of exacerbations were mainly obtained from Hettle et al, ${ }^{26}$ who in turn derived estimates from UPLIFT. ${ }^{16}$ GLY was assumed to be equivalent to TIO in terms of effects on overall lung function $\left(\mathrm{FEV}_{1}\right)$. The rationale for this assumption is well founded. Recent trials (GLOW1-2) ${ }^{27}$ and indeed SPARK, ${ }^{19}$ as well as network meta-analyses, ${ }^{28,29}$ have shown comparability in terms of the effect on FEV between TIO and GLY and other LAMAs. Thus, efficacy data $\left(\mathrm{FEV}_{1}\right)$ from the TIO arm of the UPLIFT trial was used to model disease progression in both the TIO and the GLY cohorts. However, data on RRs of exacerbations for TIO versus GLY were obtained from the SPARK ${ }^{19}$ trial. Table 1 provides an overview of the sources used to model treatment efficacy.

Hettle et $\mathrm{al}^{26}$ derived sets of transition probabilities for TIO and usual care arms using data from UPLIFT. A separate set of transition probabilities was obtained for the first cycle on treatment in order to capture the initial 30-day effect of TIO on $\mathrm{FEV}_{1} \cdot{ }^{26}$ In the base case analysis, patients were assumed to be on treatment for 4 years from the start of simulation, based on the observed treatment duration in UPLIFT. ${ }^{16}$ The 
assumption was made to ensure that results were not driven by unrealistic assumptions about treatment duration (some share of patients will in practice discontinue treatment). As there is little persistence in the effect of LAMAs after stopping treatment, transition probabilities were assumed to return to the placebo arm (usual care) probabilities from UPLIFT in the cycle after stopping treatment. The sets of transition probabilities used in the model are shown in Table 2.

Rates of exacerbations for usual care and TIO were obtained from Hettle et $\mathrm{al}^{26}$ (derived from UPLIFT) and recalculated to reflect 3-month risks. RRs of exacerbations for TIO versus GLY were obtained from SPARK. ${ }^{19}$ Usual care probabilities were applied in cycles off treatment.

Table 3 shows the risks of different types of exacerbations by GOLD state for the two treatment alternatives as well as for cycles off treatment (usual care). The efficacy of

Table I Source overview of clinical inputs

\begin{tabular}{lll}
\hline Clinical input & TIO & GLY \\
\hline $\begin{array}{l}\text { Transition probabilities } \\
\text { Cycles on treatment (year 0-4) }\end{array}$ & $\begin{array}{l}\text { UPLIFT } \\
\text { (TIO arm) } \\
\text { UPLIFT (usual } \\
\text { care arm) }\end{array}$ & $\begin{array}{l}\text { UPLIFT } \\
\text { (TIO arm) }^{\mathrm{a}} \\
\text { UPLIFT (usual } \\
\text { care arm) }\end{array}$ \\
$\begin{array}{ll}\text { Probabilities of exacerbations } \\
\text { Baseline risks of exacerbations }\end{array}$ & $\begin{array}{l}\text { UPLIFT } \\
\text { (TIO arm) }\end{array}$ & $\begin{array}{l}\text { UPLIFT } \\
\text { (TIO arm) }\end{array}$ \\
RRs & $\begin{array}{l}\text { (N/A baseline } \\
\text { applied) }\end{array}$ & $\begin{array}{l}\text { SPARK RR } \\
\text { TIO/GLYc }\end{array}$ \\
\hline
\end{tabular}

Notes: aSeveral trials have shown comparable efficacy between tiotropium and glycopyrronium in terms of overall lung function $\left(\mathrm{FEV}_{1}\right)$. ${ }^{\mathrm{b}} \mathrm{As}$ there is little persistence in the effect of LAMAs after stopping treatment, transition probabilities were assumed to return to the placebo arm (usual care) probabilities in the cycle after stopping treatment. 'Applied to baseline risks of exacerbations from UPLIFT (TIO arm). Adapted from Wedzicha et al ${ }^{19}$ and Hettle et al. ${ }^{27}$

Abbreviations: TIO, Tiotropium; GLY, glycopyrronium; UPLIFT, Understanding Potential Long-term Impacts on Function with Tiotropium; N/A, not applicable; RR, relative risk; $\mathrm{FEV}_{1}$, forced expiratory volume in I second.
TIO versus GLY was modeled solely based on the risks of exacerbations observed in SPARK (GLY/TIO RR non-SevEx: 0.98 and GLY/TIO RR SevEx: 1.43).

\section{Epidemiological data}

Baseline age-differentiated mortality for the general population in each country was obtained from the national and World Health Organization databases on causes of deaths. ${ }^{30-33}$ From the databases, it was possible to discern the share of total deaths that were related to COPD and to factor these out of the baseline mortality rates for the general population. The corrected and age-differentiated mortality rates for the general population were then used as baseline rates, on top of which excess mortality related to COPD was added. Point estimates for excess mortality associated with each GOLD state were obtained from Garcia-Aymerich et $\mathrm{al}^{11}$ and extrapolated over age intervals using the change in RR between age groups from Hoogendoorn et al. ${ }^{34}$ Similarly, age-differentiated excess mortality rates for severe exacerbations were generated using point estimates and changes in RRs between age groups from Hoogendoorn et al. ${ }^{34}$ Finally, it was assumed that "nonsevere

Table 3 Model probabilities of exacerbations by GOLD states

\begin{tabular}{lllllllllll}
\hline Event/GOLD & \multicolumn{3}{c}{ Off treatment } & \multicolumn{3}{c}{ Tiotropium } & \multicolumn{3}{c}{ Glycopyrronium } \\
\cline { 2 - 9 } & II & III & IV & II & III & IV & II & III & IV \\
\hline $\begin{array}{l}\text { No } \\
\text { exacerbation }\end{array}$ & 0.84 & 0.78 & 0.73 & 0.87 & 0.8 I & 0.77 & 0.86 & 0.79 & 0.74 \\
$\begin{array}{l}\text { Nonsevere } \\
\text { exacerbation }\end{array}$ & 0.14 & 0.17 & 0.18 & 0.11 & 0.14 & 0.15 & 0.11 & 0.14 & 0.14 \\
$\begin{array}{l}\text { Severe } \\
\text { exacerbation }\end{array}$ & 0.02 & 0.05 & 0.08 & 0.02 & 0.05 & 0.08 & 0.03 & 0.07 & 0.12 \\
\hline
\end{tabular}

Notes: Usual care probabilities from UPLIFT were used in cycles off treatment. Probabilities reflect 3-month risks. Data from Hettle et al ${ }^{27}$ (derived from UPLIFT), SPARK, ${ }^{19}$ and own calculations.

Abbreviations: GOLD, Global Initiative for Chronic Obstructive Lung Disease; UPLIFT, Understanding Potential Long-term Impacts on Function with Tiotropium.

Table 2 Model transition probabilities by GOLD states

\begin{tabular}{|c|c|c|c|c|c|c|c|}
\hline & & \multicolumn{3}{|l|}{ First cycle } & \multicolumn{3}{|c|}{ Subsequent cycles } \\
\hline & & \multicolumn{3}{|l|}{ To } & \multicolumn{3}{|l|}{ To } \\
\hline & & GOLD II & GOLD III & GOLD IV & GOLD II & GOLD III & GOLD IV \\
\hline \multicolumn{8}{|c|}{ TIO/GLY } \\
\hline \multirow[t]{3}{*}{ From } & GOLD II & 0.92 & 0.08 & 0.00 & 0.92 & 0.08 & 0.00 \\
\hline & GOLD III & 0.17 & 0.80 & 0.03 & 0.08 & 0.88 & 0.04 \\
\hline & GOLD IV & 0.03 & 0.28 & 0.69 & 0.00 & 0.12 & 0.88 \\
\hline \multicolumn{8}{|c|}{ Off treatment } \\
\hline \multirow[t]{3}{*}{ From } & GOLD II & 0.86 & 0.13 & 0.01 & 0.91 & 0.09 & 0.00 \\
\hline & GOLD III & 0.13 & 0.81 & 0.06 & 0.08 & 0.88 & 0.04 \\
\hline & GOLD IV & 0.02 & 0.22 & 0.76 & 0.00 & 0.13 & 0.87 \\
\hline
\end{tabular}

Notes: For TIO and GLY cohorts, usual care probabilities were assumed to hold when off treatment. Probabilities have been recalculated to reflect 3-month probabilities. Death has been excluded, as this model carries separate mortality rates derived for each country's population. Based on own calculations using data from Hettle et al ${ }^{27}$ (derived from UPLIFT ${ }^{16}$ ).

Abbreviations: GOLD II, GOLD classification indicating moderate COPD; COPD, chronic obstructive pulmonary disease; GOLD III, GOLD classification indicating severe COPD; GOLD IV, GOLD classification indicating very severe COPD; TIO, Tiotropium; GLY, glycopyrronium; UPLIFT, Understanding Potential Long-term Impacts on Function with Tiotropium. 
exacerbations" did not additionally impact mortality, that is, the state-specific mortality rates were assumed to hold in cycles where these events occurred.

\section{Health economic data}

Drug costs for TIO and GLY were obtained from relevant sources in each country. The drug costs $(€ 2014)$ per patient per day for each country are displayed in Table 4 .

Direct costs, presented in Table 5, were assigned to the different state-event combinations. Each cycle that a patient spent in one of the GOLD states had an associated maintenance cost plus an extra cost for the particular event (no exacerbation, nonsevere exacerbation, or severe exacerbation) occurring during that cycle. The costs of exacerbations were obtained from relevant sources in each country.

The baseline utility weights for each GOLD state were obtained from relevant sources in each country. In the case of CAN, UK weights were used due to the lack of data on Canadian COPD patients. Decrements associated with nonsevere exacerbations (1.66\%) and severe exacerbations $(4.82 \%)$ were obtained from Hoogendorn et al..$^{34}$ The decrements refer to the annual utility loss of nonsevere and severe exacerbations, respectively. The utility weight associated with each stateevent combination was recalculated to reflect the cycle length (3 months), and it was assumed that the decrements lasted for the entire duration of the model cycle. Table 6 shows the annual utility weights associated with each state-event combination.

Table 4 Drug costs (€20I4) per patient per day for each country

\begin{tabular}{lllll}
\hline Therapy/country & CAN & ESP & SWE & UK \\
\hline
\end{tabular}

\begin{tabular}{llllll}
\hline Spiriva Handihaler (tiotropium $18 \mu \mathrm{g})$ & 1.48 & 0.97 & 1.40 & 1.39
\end{tabular}

$\begin{array}{llllll}\text { Seebri Breezhaler (glycopyrronium } 44 \mu \mathrm{g}) & 1.21 & 0.94 & 1.15 & 1.14\end{array}$

Notes: Ex-rates 2014: CAN (C\$ to $€:$ 0.68), Bank of Canada ${ }^{40}$; SWE (SEK to $€: 0.11$ ), Sveriges Riksbank ${ }^{41}$; UK ( $€$ to $€:$ I.24), Bank of England. ${ }^{42}$ Dosing: one capsule per day. Adapted from Ontario Drug Benefit Formulary ${ }^{35}$ (CAN), botplus + deductions ${ }^{36,37}$ (ESP), the Dental and Pharmaceuticals Benefits Agency (TLV) ${ }^{38}$ (SWE), and $\mathrm{MIMS}^{39}$ (UK).

Abbreviations: CAN, Canada; ESP, Spain, SWE, Sweden; SEK, Swedish krona; MIMS, monthly index of medical specialties; TLV, Tandvårds- och läkemedelsförmånsverket [dental and pharmaceutical benefits agency].

\section{Results}

\section{Base case}

Base case results are presented in Table 7. TIO added 0.21 (CAN), 0.25 (ESP), 0.23 (SWE), and 0.23 (UK) qualityadjusted life years (QALYs) compared to GLY over the lifetime of the average patient. The incremental costs (€2014) compared to GLY were $-€ 623$ (CAN), $€ 1,066$ (ESP), $€ 264$ (SWE), and $€ 169$ (UK). Thus, in the case of UK and CAN, TIO was found to be cost saving, as it was both more effective and less costly than GLY. For ESP and SWE, the cost per QALY (incremental cost-effectiveness ratios [ICERs]) was positive but small, at $€ 4,281$ and $€ 1,137$, respectively. The estimated ICERs are well below the existing willingness-to-pay thresholds for ESP $(€ 30,000)$ and SWE $(\sim € 50,000-€ 100,000)$.

\section{Sensitivity analyses}

Deterministic one-way sensitivity analyses were performed on key model parameters, in order to assess their impact on the main results.

Table 8 shows how the ICERs were affected when varying key model parameters one at a time. The scenarios that consistently impacted the ICER the most were a shorter time horizon and a lower RR of severe exacerbations. Shortening the time horizon to 5 years lowered the ICER. Lowering the

Table 6 Utility weights by GOLD state and type of exacerbation

\begin{tabular}{llllllllll}
\hline Event/GOLD & \multicolumn{2}{l}{ CAN/UK } & \multicolumn{3}{c}{ ESP } & \multicolumn{5}{c}{ SWE } \\
\cline { 2 - 9 } & II & III & IV & II & III & IV & II & III & IV \\
\hline No Ex & 0.79 & 0.75 & 0.65 & 0.82 & 0.72 & 0.57 & 0.73 & 0.74 & 0.52 \\
Non-SevEx & 0.77 & 0.74 & 0.64 & $0.8 I$ & 0.71 & 0.56 & 0.72 & 0.73 & $0.5 I$ \\
SevEx & 0.74 & 0.70 & 0.61 & 0.78 & 0.69 & 0.54 & 0.69 & 0.70 & 0.49
\end{tabular}

Notes: Weights for mild and moderate exacerbations were merged (averaged) if necessary to form "nonsevere exacerbation". Utility weights were derived using the EQ-5D questionnaire. Data from Hettle et $\mathrm{a}^{26}(\mathrm{CAN} / \mathrm{UK})$, Miravitles et $\mathrm{a}^{49}(\mathrm{ESP})$, and Stahl et al $\left.\right|^{50}(\mathrm{SWE})$.

Abbreviations: GOLD, Global Initiative for Chronic Obstructive Lung Disease; GOLD II, GOLD classification indicating moderate COPD; COPD, chronic obstructive pulmonary disease; GOLD III, GOLD classification indicating severe COPD; GOLD IV, GOLD classification indicating very severe COPD; CAN, Canada; ESP, Spain, SWE, Sweden; No Ex, no exacerbation; Non-SevEx, nonsevere exacerbation; SevEx, severe exacerbation; EQ-5D, Euroqol 5 dimension.

Table 5 Direct costs (€20I4) by GOLD state and type of event

\begin{tabular}{|c|c|c|c|c|c|c|c|c|c|c|c|c|}
\hline \multirow[t]{2}{*}{ Event/GOLD } & \multicolumn{3}{|c|}{ CAN $^{43,44}$} & \multicolumn{3}{|c|}{$E^{2} P^{45,46}$} & \multicolumn{3}{|c|}{ SWE ${ }^{47,48}$} & \multicolumn{3}{|l|}{ UK ${ }^{26}$} \\
\hline & II & III & IV & II & III & IV & II & III & IV & II & III & IV \\
\hline No Ex & 95 & 284 & 416 & 366 & 1,060 & $|, 75|$ & $14 \mid$ & 333 & 472 & 150 & 321 & 531 \\
\hline Non-SevEx & 391 & 580 & 712 & 669 & 1,363 & 2,054 & 486 & 678 & 817 & 153 & 474 & 684 \\
\hline SevEex & 7,108 & 7,297 & 7,428 & 1,822 & 2,516 & 3,207 & 3,058 & 3,250 & 3,389 & 4,832 & 5,153 & 5,363 \\
\hline
\end{tabular}

Notes: Ex-rates 2014: CAN (C\$ to $€: 0.68)^{40}$; SWE (SEK to $\left.€: 0.11\right)^{41}$; UK ( $€$ to $\left.€: 1.24\right)^{42}$ Where necessary, costs have been inflated to 2014 year prices and recalculated to reflect 3-month cycle.

Abbreviations: GOLD, Global Initiative for Chronic Obstructive Lung Disease; GOLD II, GOLD classification indicating moderate COPD; COPD, chronic obstructive pulmonary disease; GOLD III, GOLD classification indicating severe COPD; GOLD IV, GOLD classification indicating very severe COPD; CAN, Canada; ESP, Spain, SWE, Sweden; No Ex, no exacerbation; Non-SevEx, nonsevere exacerbation; SevEx, severe exacerbation; SEK, Swedish krona. 
Table 7 Base case results

\begin{tabular}{|c|c|c|c|}
\hline & Tiotropium & Glycopyrronium & Difference \\
\hline \multicolumn{4}{|l|}{ CAN } \\
\hline \multicolumn{4}{|l|}{ Costs $(€)$} \\
\hline Treatment costs & 1,933 & $\mathrm{I}, 554$ & 380 \\
\hline Direct costs & $20,|7|$ & 21,174 & $-1,003$ \\
\hline Total direct costs & 22,105 & 22,728 & -623 \\
\hline \multicolumn{4}{|l|}{ Health outcomes } \\
\hline QALYs & 6.75 & 6.54 & 0.21 \\
\hline Life years & 9.00 & 8.72 & 0.28 \\
\hline ICER $(€)$ & & & TIO dom \\
\hline \multicolumn{4}{|l|}{ ESP } \\
\hline \multicolumn{4}{|l|}{ Costs $(€)$} \\
\hline Treatment costs & 1,318 & 1,255 & 63 \\
\hline Direct costs & 39,812 & 38,809 & 1,003 \\
\hline Total direct costs & 41,129 & 40,063 & 1,066 \\
\hline \multicolumn{4}{|l|}{ Health outcomes } \\
\hline QALYs & 7.77 & 7.52 & 0.25 \\
\hline Life years & 10.47 & 10.14 & 0.34 \\
\hline $\operatorname{ICER}(€)$ & & & $4,28 I$ \\
\hline \multicolumn{4}{|l|}{ SWE } \\
\hline \multicolumn{4}{|l|}{ Costs $(€)$} \\
\hline Treatment costs & 1,898 & $\mathrm{I}, 532$ & 366 \\
\hline Direct costs & $|8| 7 \mid$, & 18,273 & -102 \\
\hline Total direct costs & 20,069 & 19,805 & 264 \\
\hline \multicolumn{4}{|l|}{ Health outcomes } \\
\hline QALYs & 7.25 & 7.02 & 0.23 \\
\hline Life years & 10.26 & 9.93 & 0.33 \\
\hline $\operatorname{ICER}(€)$ & & & 1,137 \\
\hline \multicolumn{4}{|l|}{ UK } \\
\hline \multicolumn{4}{|l|}{ Costs $(€)$} \\
\hline Treatment costs & 1,865 & $\mathrm{I}, 503$ & 362 \\
\hline Direct costs & 19,285 & 19,816 & -531 \\
\hline Total direct costs & 21,150 & 21,319 & -169 \\
\hline \multicolumn{4}{|l|}{ Health outcomes } \\
\hline QALYs & 7.37 & 7.13 & 0.23 \\
\hline Life years & 9.82 & 9.51 & 0.31 \\
\hline ICER $(€)$ & & & TIO dom \\
\hline
\end{tabular}

Notes: Discount rates: all costs and effects are discounted at an annual rate of CAN, 5\%; ESP, 3\%; SWE, 3\%; and UK, 3.5\%.

Abbreviations: QALYs, quality-adjusted life years; ICER, incremental cost-effectiveness ratio; CAN, Canada; ESP, Spain; SWE, Sweden; TIO dom, tiotropium dominating.

RR of severe exacerbations to the $95 \%$ lower limit found in SPARK (GLY/TIO RR SevEx: 1.05) increased the ICER by $>€ 10,000$ in CAN, SWE, and UK.

Figure 2 further explores the impact of the most important factor in explaining the results, the RR of severe exacerbations. When it is assumed that TIO and GLY are equally efficacious (RR SevEx: 1.00), TIO is dominated by GLY. This is a trivial result given that the two therapies are equally efficacious in every other regard and that GLY is less expensive. However, for CAN, SWE, and UK, as the RR increases in favor of TIO, the ICER quickly declines. For ESP, the decline is not as large, due to the smaller price difference between TIO and GLY in ESP ( $3 \%$ in ESP vs $22 \%$ in the other countries). Nevertheless, already at an RR of 1.02-1.03, TIO can be considered borderline cost-effective by most countries' willingness-to-pay thresholds. At an RR of 1.43 (found in SPARK ${ }^{19}$ ), TIO would certainly be considered a cost-effective alternative to GLY.

\section{Discussion}

The primary objective of this study was to assess the costeffectiveness of TIO monotherapy compared to GLY monotherapy in moderate to very severe COPD patients in CAN, ESP, SWE, and the UK. TIO was found to be cost-effective compared to GLY in all four countries. The results were to a large extent driven by the lower risk of severe exacerbations observed in the TIO cohort.

The SPARK estimate of relative efficacy of severe exacerbations (GLY/TIO RR SevEx: $1.43, P=0.025)$ is high compared to existing reviews and network meta-analyses of bronchodilators in COPD. ${ }^{28,51}$ These studies do not find any 
Table 8 One-way sensitivity analysis (ICER €20I4)

\begin{tabular}{|c|c|c|c|c|c|}
\hline Variable of interest & Input & CAN & ESP & SWE & UK \\
\hline Base case & & TIO dom & 4,281 & $\mathrm{I}, \mathrm{I} 37$ & TIO dom \\
\hline \multirow[t]{3}{*}{ Discount rates } & Costs: $0 \%$, effects: $0 \%$ & TIO dom & 4,505 & $\mathrm{I}, 442$ & 81 \\
\hline & Costs: $6 \%$, effects: $6 \%$ & TIO dom & 4,039 & 814 & TIO dom \\
\hline & Costs: $6 \%$, effects: $0 \%$ & TIO dom & 2,328 & 475 & TIO dom \\
\hline \multirow[t]{3}{*}{ Time horizon } & 5 years & TIO dom & $\mathrm{I}, 174$ & TIO & TIO dom \\
\hline & 10 years & TIO dom & 3,617 & 227 & TIO dom \\
\hline & 20 years & TIO dom & 4,212 & $\mathrm{I}, 047$ & TIO dom \\
\hline \multirow[t]{3}{*}{ Treatment duration } & I year & TIO dom & 4,147 & 1,070 & TIO dom \\
\hline & 10 years & TIO dom & 4,458 & 1,316 & TIO dom \\
\hline & Life (35 years) & TIO dom & 4,707 & $|, 63|$ & TIO dom \\
\hline \multirow[t]{2}{*}{ Sex } & Males only & TIO dom & 4,174 & 1,048 & TIO dom \\
\hline & Females only & TIO dom & 4,364 & 1,213 & TIO dom \\
\hline \multirow[t]{2}{*}{ Start age } & 40 years & TIO dom & 3,504 & 216 & TIO dom \\
\hline & 80 years & 2,293 & 4,384 & 1,201 & TIO dom \\
\hline \multirow[t]{3}{*}{ GOLD start distribution } & All start in GOLD II & TIO dom & 4,136 & 1,402 & TIO dom \\
\hline & All start in GOLD III & TIO dom & 4,318 & 997 & TIO dom \\
\hline & All start in GOLD IV & TIO dom & 4,661 & 770 & TIO dom \\
\hline \multirow[t]{3}{*}{ Subgroup } & GOLD II & TIO dom & $|, 42|$ & 1,276 & TIO dom \\
\hline & GOLD III & TIO dom & 5,259 & 1,087 & TIO dom \\
\hline & GOLD IV & TIO dom & $|1,42|$ & 2,112 & TIO dom \\
\hline \multirow[t]{3}{*}{ Mortality } & $\begin{array}{l}\text { GOLD state mortality = normal mortality } \\
\text { (not adjusted for COPD) }\end{array}$ & TIO dom & 4,384 & 1,255 & TIO dom \\
\hline & $20 \%$ higher excess mortality (SevEx) & TIO dom & 4,440 & $\mathrm{I}, 355$ & TIO dom \\
\hline & $20 \%$ lower excess mortality (SevEx) & TIO dom & 4,088 & 876 & TIO dom \\
\hline \multirow[t]{3}{*}{ Effect of tiotropium on SevEx } & Low $95 \%$ Cl from SPARK (RR SevEx: I.05) & 9,942 & 5,875 & 12,509 & 10,102 \\
\hline & High $95 \% \mathrm{Cl}$ from SPARK ${ }^{\mathrm{a}}$ (RR SevEx: I.97) & TIO dom & 4,161 & 308 & TIO dom \\
\hline & RR SevEx: I.00 for GOLD II patients & TIO dom & 4,579 & 1,691 & TIO dom \\
\hline \multirow[t]{2}{*}{ Direct costs of SevEx } & $20 \%$ higher & TIO dom & 3,909 & 611 & TIO dom \\
\hline & $20 \%$ lower & TIO dom & 4,592 & 1,576 & TIO dom \\
\hline \multirow[t]{2}{*}{ QoL loss of SevEx exacerbations } & $0 \%$ loss & TIO dom & 4,309 & 1,145 & TIO dom \\
\hline & $20 \%$ loss & TIO dom & 4,195 & 1,113 & TIO dom \\
\hline
\end{tabular}

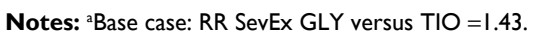

Abbreviations: ICER, incremental cost-effectiveness ratio; CAN, Canada; ESP, Spain; SWE, Sweden; GOLD, Global Initiative for Chronic Obstructive Lung Disease; GOLD II, GOLD classification indicating moderate COPD; GOLD III, GOLD classification indicating severe COPD; GOLD IV, GOLD classification indicating very severe COPD; COPD, chronic obstructive pulmonary disease; SevEx, severe exacerbation; Cl, confidence interval; RR, relative risk; QoL, quality of life; TIO dom, tiotropium dominating; GLY dom, glycopyrronium dominating; TIO, tiotropium; GLY, glycopyrronium.

large and significant difference between LAMAs (eg, TIO, GLY, and aclidinium) either when it comes to effect on lung function or exacerbations. ${ }^{28,51}$ However, there are still inherent problems with comparing trials that have differing designs, that allow different co-treatments, and that have varying length of follow-up. ${ }^{52}$ These problems will be important when comparing exacerbation outcomes indirectly. Comparing SPARK to other relevant trials (eg, GLOW2 ${ }^{27}$ ), SPARK had longer follow-up, was more favorably designed to detect moderate to severe exacerbations, and included more severe patients. This likely affected the ability to detect and record severe events.

Exacerbation prevention is an important goal in the management of COPD and that cost-effectiveness is highly dependent on the ability to prevent exacerbations, particularly severe ones that lead to costly hospitalizations. This study has shown that given the best available head-to-head evidence on exacerbations to date (SPARK), the balance would likely sway in favor of TIO being a cost-effective alternative to GLY. In fact, our findings suggest that a much lower RR of severe exacerbations than the one found in SPARK would suffice to render TIO a cost-effective intervention compared to GLY.

The results presented here compare two dry powder inhalers (Spiriva HandiHaler and Seebri Breezhaler). TIO can also be delivered using the Respimat ${ }^{\circledR}$ inhaler, a soft mist inhaler (inhalation spray). The Tiotropium Safety and Performance in Respimat (TIOSPIR) trial showed that Respimat had a safety profile and exacerbation efficacy similar to that of the HandiHaler device. ${ }^{53}$ In addition, a head-to-head in vitro dose comparison between Respimat and Breezhaler found that Respimat delivered significantly higher doses of the drug to the lung (Respimat: 60-70 [\% not determined]; Breezhaler 50-60 [\% not determined]).$^{54}$ These findings suggest that Respimat can successfully deliver TIO with maintained efficacy and safety and with far less drug deposition in the upper throat. In light of these 


\section{0,000}

80,000

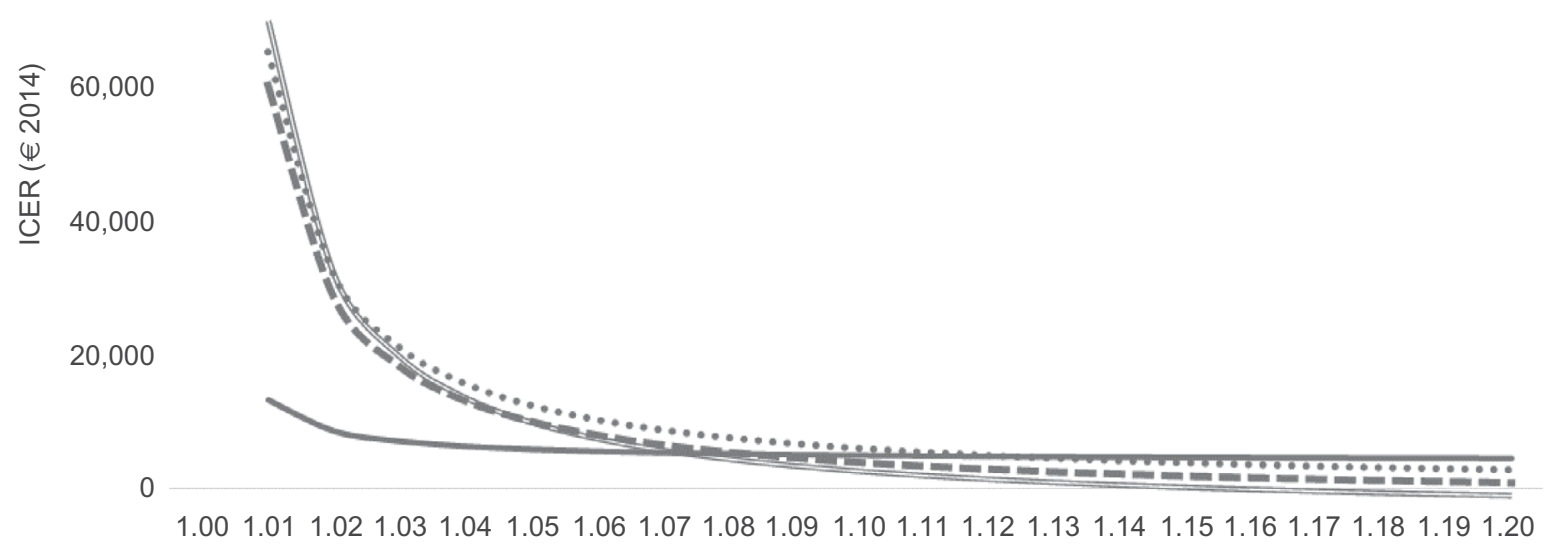

$-20,000$

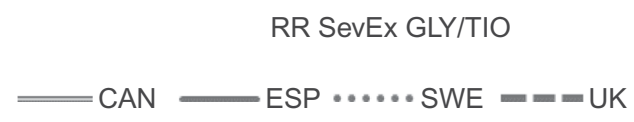

Figure 2 Impact of RR SevEx on ICER.

Abbreviations: RR, relative risk; SevEx, severe exacerbation; ICER, incremental cost-effectiveness ratio; GLY, glycopyrronium; TIO, tiotropium; CAN, Canada; ESP, Spain; SWE, Sweden.

findings, we expect the cost-effectiveness results to be applicable also to cases where TIO is delivered via the Respimat device.

Extensive sensitivity analyses were conducted to assess the impact of key parameters on the main results. The relative efficacy of the interventions, particularly in preventing severe exacerbations, played an important role in explaining costeffectiveness. In this regard, it is important to remember the basic design and purpose of the UPLIFT and SPARK trials and how these factors potentially affected the results. The purpose of the UPLIFT trial was to assess the effect of the interventions on overall lung function; exacerbations were only a secondary objective. Additionally, the patients received usual non-LAMA care in both arms. This included LABA and/or corticosteroid therapy in a majority of the patients enrolled. The trial, not being primarily designed to detect exacerbations and the use of alternative inhaled therapy, likely pushed rates of exacerbations downward. This may explain why the study found no significant difference in the rates of severe exacerbations between the two arms.

As opposed to the UPLIFT trial, the SPARK trial was designed specifically to detect moderate and severe exacerbations. ${ }^{16,19}$ High-risk patients, that is, those having had at least one moderate exacerbation in the past year, were enrolled and randomly assigned to receive either QVA149 (LAMA/ LABA combination), TIO, or GLY. Importantly, patients who were receiving LABA therapy discontinued the therapy upon enrolling in the trial, although ICS therapy continued. Indeed, these circumstances suggest that the SPARK trial was more favorably designed to detect and record exacerbations. Having said that, there were only 364 severe exacerbations reported in total across all three arms in SPARK. The low number of observed severe exacerbations naturally introduces some uncertainty in the estimate of the RR between TIO and GLY. It is important to keep in mind that, as opposed to mild and moderate exacerbations, severe exacerbations are infrequent events in COPD. In addition, SPARK did not include a placebo arm, which means that all arms in the trial contained active therapy with the specific aim of lowering rates of exacerbations. ${ }^{19}$ These circumstances suggest that even if a trial is favorably designed to detect severe exacerbations, it is always going to be difficult to amass a large study population to record many severe exacerbations. Future research should continue to focus efforts on disentangling the relative efficacy of different types of bronchodilators in preventing these rare events, as they are important factors explaining morbidity, mortality, and cost-effectiveness in COPD.

A potential drawback with this study, like any other utilizing trial data, is that the patient population might be somewhat different from the actual population of COPD patients (GOLD II-IV). Measures were taken to limit this potential bias, eg, by 
applying country-specific mortality rates. Furthermore, one should interpret differences between countries with caution, as there are substantial differences in the organization of health care and its funding. Differences in the way unit costs are estimated may also play an important role. Finally, it is important to keep in mind that the model presented here evaluates an exploratory scenario where the two cohorts are equal in every other regard except in terms of the risk of experiencing exacerbation.

\section{Conclusion}

Clinical data from UPLIFT and SPARK studies were incorporated in a Markov cohort model, which explicitly modeled the effects of exacerbations. Cost-effectiveness of TIO was assessed relative to GLY. TIO was found to be cost-effective relative to GLY given the current state of clinical evidence. The findings were to a large extent driven by TIO being relatively efficacious in preventing severe exacerbations, based on the findings in the SPARK trial.

\section{Acknowledgments}

The abstract of this paper was presented at the ISPOR 20th Annual International Meeting, Philadelphia, PA, USA, on May 16-20, 2015, as a poster presentation with interim findings (excluding Spain). The poster's abstract was published in "Poster Abstracts" in Value in Health May 2015, Vol 18, Issue 3, Pages A173-A174. In addition, an analysis using the same model has been published during 2015.

\section{Author contributions}

All authors contributed toward data analysis, drafting and critically revising the paper and agree to be accountable for all aspects of the work.

\section{Disclosure}

The study was sponsored by Boehringer Ingelheim (a manufacturer of Spiriva [tiotropium]). OE and FB independently designed and executed the study. FA, JF, AT, MEO, CC, and $\mathrm{MB}$ are employees of Boehringer Ingelheim. The authors report no other conflicts of interest in this work.

\section{References}

1. Rycroft CE, Heyes A, Lanza L, Becker K. Epidemiology of chronic obstructive pulmonary disease: a literature review. Int J Chron Obstruct Pulmon Dis. 2011;7:457-494.

2. Mannino DM, Buist AS. Global burden of COPD: risk factors, prevalence, and future trends. Lancet. 2007;370(9589):765-773.

3. Buist AS, McBurnie MA, Vollmer WM, et al. International variation in the prevalence of COPD (the BOLD Study): a population-based prevalence study. Lancet. 2007;370(9589):741-750.

4. Halbert R, Natoli J, Gano A, Badamgarav E, Buist A, Mannino DM. Global burden of COPD: systematic review and meta-analysis. Eur Respir J. 2006;28(3):523-532.
5. Global Initiative for Chronic Obstructive Lung Disease (GOLD). Global Strategy for the Diagnosis, Management, and Prevention of Chronic Obstructive Pulmonary Disease. GOLD; 2016:1-111.

6. Guarascio AJ, Ray SM, Finch CK, Self TH. The clinical and economic burden of chronic obstructive pulmonary disease in the USA. Clinicoecon Outcomes Res. 2013;5:235-245.

7. Mapel DW, Roberts MH. New clinical insights into chronic obstructive pulmonary disease and their implications for pharmacoeconomic analyses. Pharmacoeconomics. 2012;30(10):869-885.

8. Mapel DW, Robinson SB, Dastani HB, Shah H, Phillips AL, Lydick E. The direct medical costs of undiagnosed chronic obstructive pulmonary disease. Value Health. 2008;11(4):628-636.

9. Mapel DW, Hurley JS, Frost FJ, Petersen HV, Picchi MA, Coultas DB. Health care utilization in chronic obstructive pulmonary disease: a case-control study in a health maintenance organization. Arch Intern Med. 2000;160(17):2653-2658.

10. Halpin DM. Health economics of chronic obstructive pulmonary disease. Proc Am Thorac Soc. 2006;3(3):227-233.

11. Garcia-Aymerich J, Pons IS, Mannino DM, Maas AK, Miller DP, Davis KJ. Lung function impairment, COPD hospitalisations and subsequent mortality. Thorax. 2011;66(7):585-590.

12. Hoogendoorn M, Hoogenveen RT, Rutten-van Mölken MP, Vestbo J, Feenstra TL. Case fatality of COPD exacerbations: a meta-analysis and statistical modelling approach. Eur Respir J. 2011;37(3):508-515.

13. Solem CT, Sun SX, Sudharshan L, Macahilig C, Katyal M, Gao X. Exacerbation-related impairment of quality of life and work productivity in severe and very severe chronic obstructive pulmonary disease. Int $J$ Chron Obstruct Pulmon Dis. 2013;8:641-652.

14. Seemungal TA, Donaldson GC, Paul EA, Bestall JC, Jeffries DJ, Wedzicha JA. Effect of exacerbation on quality of life in patients with chronic obstructive pulmonary disease. Am J Respir Crit Care Med. 1998;157(5):1418-1422.

15. Wedzicha JA, Decramer M, Seemungal TA. The role of bronchodilator treatment in the prevention of exacerbations of COPD. Eur Respir J. 2012;40(6):1545-1554.

16. Tashkin DP, Celli B, Senn S, et al. A 4-year trial of tiotropium in chronic obstructive pulmonary disease. $N$ Engl J Med. 2008;359(15): 1543-1554.

17. Decramer ML, Chapman KR, Dahl R, et al. Once-daily indacaterol versus tiotropium for patients with severe chronic obstructive pulmonary disease (INVIGORATE): a randomised, blinded, parallel-group study. Lancet Respir Med. 2013;1(7):524-533.

18. Vogelmeier C, Hederer B, Glaab T, et al. Tiotropium versus salmeterol for the prevention of exacerbations of COPD. $N$ Engl J Med. 2011;364(12):1093-1103.

19. Wedzicha JA, Decramer M, Ficker JH, et al. Analysis of chronic obstructive pulmonary disease exacerbations with the dual bronchodilator QVA149 compared with glycopyrronium and tiotropium (SPARK): a randomised, double-blind, parallel-group study. Lancet Respir Med. 2013;1(3):199-209.

20. Keating GM. Tiotropium bromide inhalation powder. Drugs. 2012;72(2): 273-300.

21. van Mölken MR, Goossens L. Cost effectiveness of pharmacological maintenance treatment for chronic obstructive pulmonary disease. Pharmacoeconomics. 2012;30(4):271-302.

22. Global Initiative for Chronic Obstructive Lung Disease (GOLD). Pocket Guide to COPD Diagnosis, Management, and Prevention. GOLD; 2013:30.

23. Price D, Asukai Y, Ananthapavan J, Malcolm B, Radwan A, Keyzor I. A UK-based cost-utility analysis of indacaterol, a once-daily maintenance bronchodilator for patients with COPD, using real world evidence on resource use. Appl Health Econ Health Policy. 2013;11(3):259-274.

24. Hoogendoorn M, Kappelhoff BS, Overbeek JA, Wouters EF, Rutten-van Molken MP. Which long-acting bronchodilator is most cost-effective for the treatment of COPD? Neth J Med. 2012;70(8):357-364.

25. Eklund O, Afzal F, Borgström F. Cost-effectiveness of tiotropium versus usual care and glycopyrronium in the treatment of chronic obstructive pulmonary disease in Sweden. Cost Eff Resour Alloc. 2015;13(1):1. 
26. Hettle R, Wouters H, Ayres J, et al. Cost-utility analysis of tiotropium versus usual care in patients with $\mathrm{COPD}$ in the UK and Belgium. Respir Med. 2012;106(12):1722-1733.

27. D'Urzo A, Kerwin E, Overend T, D'Andrea P, Chen H, Goyal P. Once daily glycopyrronium for the treatment of COPD: pooled analysis of the GLOW1 and GLOW2 studies. Curr Med Res Opin. 2013;30(3):493-508.

28. Cope S, Donohue JF, Jansen JP, et al. Comparative efficacy of longacting bronchodilators for COPD-a network meta-analysis. Respir Res. 2013;14(1):100

29. Karabis A, Lindner L, Mocarski M, Huisman E, Greening A. Comparative efficacy of aclidinium versus glycopyrronium and tiotropium, as maintenance treatment of moderate to severe COPD patients: a systematic review and network meta-analysis. Int $J$ Chron Obstruct Pulmon Dis. 2013;8:405-423.

30. ons.gov.uk [webpage on the Internet]. Deaths Registered in England and Wales 2012. 2012. Available from: http://www.ons.gov.uk/ons/rel/ vsob1/mortality-statistics--deaths-registered-in-england-and-wales-series-dr-/2012/dr-tables-2012.xls. Accessed November 3, 2014.

31. statcan.gc.ca [webpage on the Internet]. Deaths and Mortality Rate, by Selected Grouped Causes, Age Group and Sex in Canada. 2011. Available from: http://www5.statcan.gc.ca/cansim/a26?id=1020551\& retrLang=eng\&lang=eng. Accessed November 2, 2014.

32. socialstyrelsen.se [webpage on the Internet]. Database: Causes of Death in Sweden. 2012. Available from: http://www.socialstyrelsen.se/statistik/ statistikefteramne/dodsorsaker. Accessed March 5, 2014.

33. who.int [webpage on the Internet]. Causes of Death Query Online Database. 2015. Available from: http://apps.who.int/healthinfo/statistics/ mortality/causeofdeath_query/definitions/definitions.html. Accessed March 23, 2015.

34. Hoogendoorn M, Rutten-van Mölken M, Hoogenveen R, Al M, Feenstra T. Comparing the Cost-Effectiveness of a Wide Range of COPD Interventions Using a Stochastic, Dynamic, Population Model for COPD. Institute of Health Policy \& Management, Erasmus University Rotterdam: 2010.

35. healthinfo.moh.gov.on.ca [webpage on the Internet]. Comparative Drug Index for Ontario Canada. 2014. Available from: https://www. healthinfo.moh.gov.on.ca/formulary/. Accessed October 30, 2014.

36. botplusweb.portalfarma.com [webpage on the Internet]. Online Database of Drug Prices in Spain 2015. 2015. Available from: https://botplusweb.portalfarma.com/botplus.aspx. Accessed March 1, 2015.

37. msssi.gob.es [webpage on the Internet]. Deductions for Medications in Spain. 2014. Available from: https://www.msssi.gob.es/profesionales/ farmacia. Accessed March 1, 2015.

38. tlv.se [webpage on the Internet]. Online Database of Reimbursed Drugs in Sweden. 2014. Available from: http://www.tlv.se/beslut/sok/ lakemedel/. Accessed November 3, 2014.

39. mims.co.uk [webpage on the Internet]. Online Database of Drug Prices in the UK. 2014. Available from: http://www.mims.co.uk/. Accessed November 2, 2014.
40. bankofcanada.ca [webpage on the Internet]. Year Average of Exchange Rates 2014. 2014. Available from: http://www.bankofcanada.ca/stats/ assets/pdf/nraa-2014-en.pdf. Accessed June 22, 2015.

41. riksbank.se [webpage on the Internet]. Annual Average Exchange Rates in 2014 in Sweden. 2015. Available from: http://www.riksbank.se/sv/ Rantor-och-valutakurser/Arsgenomsnitt-valutakurser/? $\mathrm{y}=2014 \& \mathrm{~m}=12$ \&s=Comma\#search. Accessed June 22, 2015.

42. bankofengland.co.uk [webpage on the Internet]. Annual Average Exchange Rates. 2015. Available from: http://www.bankofengland. co.uk/statistics/Pages/default.aspx. Accessed June 22, 2015.

43. Spencer M, Briggs AH, Grossman RF, Rance L. Development of an economic model to assess the cost effectiveness of treatment interventions for chronic obstructive pulmonary disease. Pharmacoeconomics. 2005;23(6):619-637.

44. Mittmann N, Kuramoto L, Seung S, Haddon J, Bradley-Kennedy C, Fitzgerald J. The cost of moderate and severe COPD exacerbations to the Canadian healthcare system. Respir Med. 2008;102(3):413-421.

45. Miravitlles M, Sicras A, Crespo C, et al. Costs of chronic obstructive pulmonary disease in relation to compliance with guidelines: a study in the primary care setting. Ther Adv Respir Dis. 2013;7(3):139-150.

46. Sicras A, Huerta A, Navarro R, Ibañez J. Uso de recursos y costes asociados a las exacerbaciones de enfermedad pulmonar obstructiva crónica: estudio retrospectivo de base poblacional [Use of resources and associated costs of chronic obstructive pulmonary disease exacerbations: a population based retrospective study]. Semergen/Sociedad Espanola de Medicina Rural y Generalista. 2013;40(4):189-197.

47. Andersson F, Borg S, Jansson SA, et al. The costs of exacerbations in chronic obstructive pulmonary disease (COPD). Respir Med. 2002;96(9):700-708.

48. Jansson SA, Backman H, Stenling A, Lindberg A, Ronmark E, Lundback B. Health economic costs of COPD in Sweden by disease severity - has it changed during a ten years period? Respir Med. 2013;107(12):1931-1938

49. Miravitlles M, Huerta A, Fernández-Villar JA, et al. Generic utilities in chronic obstructive pulmonary disease patients stratified according to different staging systems. Health Qual Life Outcomes. 2014;12(1):120.

50. Stahl E, Lindberg A, Jansson S-A, et al. Health-related quality of life is related to COPD disease severity. Health Qual Life Outcomes. 2005;3(1):56.

51. Jones PW. Long-acting muscarinic antagonists for the prevention of exacerbations of chronic obstructive pulmonary disease. Ther Adv Respir Dis. 2015;9(3):84-96.

52. Jansen JP, Fleurence R, Devine B, et al. Interpreting indirect treatment comparisons and network meta-analysis for health-care decision making: report of the ISPOR Task Force on Indirect Treatment Comparisons Good Research Practices: part 1. Value Health. 2011;14(4):417-428.

53. Wise RA, Anzueto A, Cotton D, et al. Tiotropium respimat inhaler and the risk of death in COPD. $N$ Engl J Med. 2013;369(16):1491-1501.

54. Ciciliani A, Langguth P, Bickmann D, Wachtel H, Voshaar T. In vitro dose comparison of Respimat ${ }^{\circledR}$ Soft Mist ${ }^{\mathrm{TM}}$ inhaler with dry powder inhalers for COPD maintenance therapy. In: ISAM 2013 Conference; April 6-10, 2013; Chapel Hill, NC.
ClinicoEconomics and Outcomes Research

\section{Publish your work in this journal}

ClinicoEconomics and Outcomes Research is an international, peerreviewed open-access journal focusing on health technology assessment, pharmacoeconomics and outcomes research in the areas of diagnosis, medical devices, and clinical, surgical and pharmacological intervention. The economic impact of health policy and health systems

\section{Dovepress}

organization also constitute important areas of coverage. The manuscript management system is completely online and includes a very quick and fair peer-review system, which is all easy to use. Visit http://www.dovepress.com/testimonials.php to read real quotes from published authors. 